\title{
The relationship between mindfulness and positive psychology skills on response rate to pain in cancer patients
}

\author{
Fatemeh Fathi ${ }^{1}$, Morteza Akhlaghifard ${ }^{2}$
}

\begin{abstract}
This study is conducted with the aim of the relationship between mindfulness and positive psychological skills on the response rate to pain in cancer patients in Alborz province by descriptive-correlational method. The population of the study consisted of 150 cancer patients (and a sample of 116 patients) who referred to Sarhad Abad Fardis Hospital in 2016-2017. They were selected using Morgan table and by the convenience method. In order to measure the variables used in the study, three questionnaires of Mindfulness, Positive Psychology and Response rate to Pain were used. According to inferential statistics, there is a positive and significant relationship between mindfulness and positive psychological skills in cancer patients $(r=$ 0.657), which is significant at the alpha level of 0.01 . There is also a negative and significant relationship between mindfulness and response rate to pain in cancer patients $(r=-0.525)$, which is significant at the alpha level of 0.01 . The results of regression analysis indicate that among the components of mindfulness, only one dimension (non-response) with beta coefficient, $-0.52 \%$ as predictive variables has the criterion of entering the final equation of regression to explain changes of response rate to pain in cancer patients (criterion variable), the non-response alone can explain $0.27 \%$ of the response rate to pain in cancer patients.
\end{abstract}

Keywords: mindfulness, positive psychological skills, response rate to pain, cancer patients

\section{INTRODUCTION}

The increasing growth of cancer in recent decade and its harmful effects on all physical, emotional, spiritual, social and economic dimensions caused that in addition to people, the attention of specialists is focused on the disease more than ever and they introduce cancer a major health problem of century. Studies have shown that cancer exposes its patients to psychological stress, and studies have shown that between $50 \%$ and $85 \%$ of cancer patients suffer from psychiatric disorders. Cancer is associated with certain physical and psychological damage that affects the normal life of the individual (16) and encounters the possibility of balanced life with difficulty (19), people with cancer are complaining about physical pains and sometimes and persistently originated of the disease, and it is associated with many injuries (18). Undoubtedly, cancer is one of the events that people face in their lives due to bear pain caused from the disease (13). Pain is a phenomenon that involves physical, psychological and emotional processes and is a very unique experience that leads to referral of patient to clinics and health centers (4). Although pain as a general sense has biological foundations, but today, bio-psycho-social models have been developed to explain and treat pain, especially pains due to cancer, which do not consider the persistence of pain only in biological factors, including those cases in the field of cancer is the subject of mindfulness that can have positive effects in reducing perceived stress and lead the treatment process in a way that accelerate the improvement of an individual who placed mindfulness in his agenda than an individual who not has mindfulness and also brings a higher quality of life (10). In other words, psychological factors play an important role in experience and response rate to pain. This view indicates that psychology may also play a role in relieving pain symptoms during treatment. These therapies include hemnotiz, training muscle relaxation, Biofeed Bac,

\footnotetext{
Master of Clinical Psychology, Faculty of Psychology, Islamic Azad University, Karaj Branch, Alborz, Iran.

2 Assistant Professor and Head of Philosophy, Religions and Mysticism Departments, Faculty of Theology, Islamic Azad University, Karaj Branch, Alborz, Iran.
}

Received: 21 Feb 2018, Accepted: 14 Apr 2018

\author{
Correspondence: Morteza Akhlaghifard \\ Assistant Professor and Head of Philosophy, Religions and Mysticism Departments, \\ Faculty of Theology, Karaj Branch, Alborz, Iran \\ E-mail: Akhlaghifardmorteza@gmail.com
}

(C) 2019 by the authors; licensee Modestum Ltd., UK. This article is an open access article distributed under the terms and conditions of the Creative Commons Attribution License (http://creativecommons.org/licenses/by/4.0/). 
behavior change, cognitive therapy (including self-efficacy), and mixed approaches. Accordingly, in order to reduce the perceived pain level of cancer patients, their psychological state should be investigated, in order to have a more effective treatment in dealing with and response rate to pain of these patients (8). Today, mindfulness is one of the most important treatments in the world that is used in a variety of conditions and for healthy and sick individuals (2) and has a fundamental foundation in the correction and identification of the contribution of various factors (6). To be mindful evokes focus on mind and conscience, and it is contrary to the inattention or the state of automatic guidance. Mindfulness emphasizes the growth of three qualities (refraining from judgment, conscious awareness and focusing on the present moment) in attention of individual, also mindfulness is also a clear process relying on the current conditions and referring that the inability in absence from the moment causes to be disconnected between individual and reality and deprived the possibility of proper understanding from position and providing reasonable and alert answers (5). Many scientific studies have shown that the cause of many psychological problems of individuals is their lack of presence here and moment by moment of their life, while the mindfulness people perceive the internal and external facts freely and without distortion, and have a lot of ability to deal with an expand scope of thoughts, emotions and experiences (both pleasant and unpleasant). Other researchers such as Baer (9) have considered other features such as nonjudgmental attention, admission to attention, lack of reaction, ability to describe experience as its central dimensions. Therefore, the mindfulness enables us to observe wide vulnerabilities in human and face with it and challenge them that are a part of the intrinsic nature of humans. The nature of thoughtful consciousness is neither religious nor magic, but a natural subject and potentially acceptable for all of us (15). Mindfulness exercises have special attention and without judgment to some of the methods that are a powerful way to "re-establish and strengthen our communication with our inner views." This effect will lead to greater welfare and health through the ways that specific effects have on reducing the vulnerability to recurrence symptoms of depression. One of the essential factors related to mindfulness is positive thinking and its related factors. Positive psychology is a scientific study of human strengths and virtues that enable individuals and communities to be superior by emphasizing the promotion of positive performance which focuses on a high level of happiness and realization without considering individual conditions to training (21). It also emphasizes the need to understand the positive aspect of human experience and the things that value their lives, as well as to understand and improve the aspect of negative states of illness and distress and to understand the positive aspect of human experience. Positive psychology can be considered a scientific study of positive human experiences and emotions, personal capabilities and virtues and happiness of humans that is associated with mindfulness. Positive psychology is seeking to investigate issues that increase the value of proper life for living (20). Positive psychology, at the mental level, also investigates positive mental states or positive emotions such as pleasure, happiness, satisfaction with life, peace, love, intimacy. Positive mental states also include constructive thoughts about self and future; states like optimism and hope; these states also contain a sense of energy, vitality, and life, and self-esteem or the effects of positive excitements like laugh (3). According to the above mentioned, the present study is seeking to answer this fundamental question of what relationship is between mindfulness and positive psychological skills or response rate to pain in patients?

\section{RESEARCH METHODOLOGY}

This research is a descriptive -survey study. This research is applied objectively and in terms of value is comparative. The statistical population of this study is cancer patients referred to Cancer Diagnostic and Treatment Center in Alborz (Sarhad Abad District, Fardis City). The duration of distribution of questionnaires was done in two months and 166 people formed the statistical population of this study. Accordingly, the number of samples according to the Cochran formula is determined 116 people and the sampling method is convenient sampling in this research. Data collection in this research is done through library information and questionnaires. The questionnaires used in the research were:

A) Mindfulness Questionnaire (Baer et al., 2007) is a 39- item self-measurement scale that is developed by Baer et al. (9) by combining the items of Freiberg's Mindfulness Inventory (FMI), Walsh et al., 2006, Mindful Attention Awareness Scale (MAAS); Brown and Ryan, 2003, Kentuchy Inventory of Mindfulness Scale (KIMS), Baer and Smith, 2004, and the FFMQ Mindfulness Questionnaire; Baer et al., using factor analysis approach. Validity of the questionnaire: Based on the results, the internal consistency of factors was appropriate and alpha coefficient was in a range of 0.75 (non-response factor) to 0.91 (in the description factor). The correlation between the factors was moderate and in all cases was significant and in a range between 0.15 and 0.34 (Neocer, 2010; citing from Ahmadvand, 2012). Also, in a study on validity and reliability of this questionnaire in Iran, the test-retest correlation coefficients of FFMQ questionnaire in Iranian sample ranged from $r=0.57$ (non-judgmental factor) and $r=0.84$ 
(observation factor) was observed. Also, alpha coefficients were obtained in an acceptable limit (between $\alpha=0.55$ related to non-response factor and $\alpha=0.83$ related to description factor).

B) Positive Thinking Questionnaire: positive-thinking questionnaire consists of 22 phrases in four subscales (positive performance, self-efficacy, evaluation of others and hopefulness). In order to determine the structure's validity, the exploratory analysis method was utilized (main component analysis using the varimax method). The results of exploratory analysis showed that in all of the four main structures of this questionnaire i.e. positive performance, self-efficacy, evaluation of others and hopefulness, factor load values are reported higher than 0.4 that indicate the appropriateness of the validity of four structures. Accordingly, in the positive performance, 10 phrases, in the self-efficacy, 6 phrases, in the evaluation of others, 4 phrases and in hopefulness, 2 phrases are used. The reliability of this test was calculated based on Cronbach's alpha 0.94 and based on the two-half method 0.95 . And the validity of this test has been confirmed by experts (Ingram and Wisnicki, 1988). In the reliability section, the Cronbach's alpha test was used where the reliability value of each of the variables was estimated individually and was confirmed by a value above 0.7 . Also, in this research, validity and reliability of the tool were reviewed and approved by receiving views of academic professors and Cronbach's alpha test, respectively. Cronbach's alpha in this study was reported for positive performance; 0.970, self-efficacy; 0.957, evaluating others; 0.919 and hopefulness: 0.812 .

C) Response to pain questionnaire: The questionnaire has 20 sets of phrase and the aim is to measure individuals' perception from pain from various dimensions (sensory perceptions of pain, emotional perceptions of pain, evaluating perception of pain, various pains) (Malzak, 1997). To obtain the score related to each dimension, the total scores of that dimension are gathered, and to obtain the total score of questionnaire, the sum of scores of each question is calculated. Higher scores indicate higher perception of pain in the responder and vice versa. Validity and reliability of the questionnaire: In the research of Dorkin (2009), the validity of this questionnaire has been approved. Also, its reliability was calculated using Cronbach's alpha. The alpha coefficient for all dimensions ranged from 0.83 to 0.87 (citing from Koshtkar, 2016).

\section{RESEARCH FINDINGS}

The research sample shows that $54 \%$ of sample member are male and $46 \%$ of them are women, and the age range of participants in the study varies from 25 to 50 years and the most age range of participating people are between 41 and 50 . It should be noted that $16 \%$ of the subjects not have academic education and $84 \%$ have academic education.

Investigating mean and standard deviation of the main variables have shown that the components of mindfulness have the mean value above the average. Accordingly, patients have had average to above positive skills. Finally, in relation to response rate to pain, according to the interpretation of the questionnaire, the lowest and highest score can be 20 and 77, and the average score is 28.5. The mean value obtained in this study was 80.66 , which indicates the high suffering and pain perceived by patients with cancer. Also, the low standard deviation in the data indicates low level of data dispersion. The Kolmogorov-Smirnov test showed that the significance obtained is above 0.05 , and according to this result, the null hypothesis of research is acceptable and it is possible to carry out the parametric test.

At first, our correlation matrix between the research elements is mentioned with each other.

Regarding the level of significance of test, it is revealed that there is a significant relationship between mindfulness and response rate to pain in cancer patients at a $99 \%$ confidence level $(P<0.01)$. This value in general condition is equal to -0.821 . These relationships are negative. In other words, by increasing mindfulness, lower response rate to pain in cancer patients is reported. Also, there is a significant relationship between positive thinking skills and response rate to pain in patients with a $99 \%$ confidence level $(P<0.01)$. This relationship has negative correlation in amount of 0.796 between total positive skills with pain response according to Table 1.

In the following, the regression test is investigated to predict the response rate to pain by using positive thinking and mindfulness and their components. 
Table 1: Results of correlation coefficient between mindfulness and response rate to pain

\begin{tabular}{llcc}
\hline & Variable & \multicolumn{2}{c}{ Results of Pearson correlation test } \\
\hline Predictor & \multicolumn{1}{c}{ Criterion } & Correlation coefficient & Significant level \\
\hline Observation & Response to pain & -0.775 & 0.000 \\
\hline Description & Response to pain & -0.798 & 0.000 \\
\hline Action with awareness & Response to pain & -0.765 & 0.001 \\
\hline Lack of judgment & Response to pain & -0.786 & 0.000 \\
\hline Lack of reaction & Response to pain & -0.746 & 0.000 \\
\hline Mindfulness & Response to pain & 0.821 & 0.000 \\
\hline Positive performance & Response to pain & -0.751 & 0.000 \\
\hline Self-efficiency & Response to pain & -0.746 & 0.000 \\
\hline Evaluation of others & Response to pain & -0.735 & 0.001 \\
\hline Hopefulness & Response to pain & -0.734 & 0.000 \\
\hline Positive thinking & Response to pain & -0.796 & 0.000 \\
\hline
\end{tabular}

Table 2: Summary of Multivariate Regression Test in Determining Prediction of Response rate to Pain

\begin{tabular}{ccccccc}
\hline Model & ANOVA & $\mathbf{R}$ & $\begin{array}{c}\text { Coefficient of } \\
\text { determination }\end{array}$ & $\begin{array}{c}\text { Moderated coefficient } \\
\text { of determination }\end{array}$ & Estimation error & $\begin{array}{c}\text { Durbin Watson } \\
\text { static }\end{array}$ \\
\hline 1 & 0.000 & 0.798 & 0.638 & 0.634 & 7.8136 \\
\hline 2 & 0.000 & 0.847 & 0.717 & 0.712 & 6.9303 & 2.121 \\
\hline
\end{tabular}

a. Predictors: (Constant) description

b. Predictors: (Constant) description, evaluating others

c. Dependent Variable response to pain

Table 3: The coefficients of each of the variables in the measurement model

\begin{tabular}{|c|c|c|c|c|c|c|}
\hline & \multirow[t]{2}{*}{ Models } & \multicolumn{2}{|c|}{ Non-standard coefficients } & \multirow{2}{*}{$\begin{array}{c}\begin{array}{c}\text { standard } \\
\text { coefficients }\end{array} \\
\text { Beta } \\
\end{array}$} & \multirow[t]{2}{*}{ T static } & \multirow[t]{2}{*}{ Significant leve } \\
\hline & & B & Std. Error & & & \\
\hline \multirow{2}{*}{1} & (Constant) & $120 / 448$ & $2 / 901$ & & $41 / 513$ & 1000 \\
\hline & Description & $-1 / 373$ & $/ 097$ & $-/ 798$ & $-14 / 161$ & 1000 \\
\hline \multirow{3}{*}{2} & (Constant) & $125 / 171$ & $2 / 706$ & & $46 / 259$ & 1000 \\
\hline & Description & $-/ 954$ & $/ 113$ & $-/ 555$ & $-8 / 408$ & 1000 \\
\hline & $\begin{array}{l}\text { Evaluation of } \\
\text { others }\end{array}$ & $-1 / 188$ & $/ 210$ & $-/ 373$ & $-5 / 649$ & 1000 \\
\hline
\end{tabular}

In sum, the main goal of the application of multivariate regression was to create a linear combination from independent variables in such a way that show maximum correlation with the dependent variable. As a result, this linear combination can be evaluated in predicting the dependent variable and importance of each of the independent variables in predicting. To perform linear regression, several defaults are required that first will be investigated:

Given the fact that the distribution of variables is normal with Kolmogorov-Smirnov test (the variance of the errors is constant and the mean of errors are zero) and the dependent variable scale is distance, a linear regression test can be used. Another assumption is the use of the independence regression of errors (the difference between actual values and predicted values by the regression equation) from each other. If the assumption of non-correlation of errors is rejected, then it is not possible to use the regression equation. Durbin Watson Test is used to check the independence of errors. The value of the test statistic varies from one to four and if the range of this statistic is from 1.5 to 2.5 , the assumption of independence between errors is acceptable. Durbin Watson static in this study is equal to 2.121, which indicates the lack of correlation between errors and the possibility of linear regression in this research. Also, analysis of variance with a significance of $0 / 00$ also indicates the fitness of model.

Based on the results of Table 2, considering that the multivariate regression method has been used, it can be seen that among the predicted variables entered in model, only the variables of description and evaluation of others, respectively, has mindfulness and positive thinking skill, the ability to estimate response to pain of cancer patients in the form of a regression equation.

The results of the analysis of regression coefficients of model are shown in Table 3.

According to the reported results in Table 3, it can be stated that the constant coefficient, description and evaluation of others entered in this model have statistically significant difference to number 0 in their regression coefficients $(P$ $<0.05$ ). This issue is confirmed by examining the value of $t$ meaningful numbers with a value greater than 1.96. Accordingly, the predicted regression equation of response to pain in cancer patients in the present study is as follows: Response rate to pain in cancer patient $=124.44+($ Description $\times-0.954)+($ evaluation of others $\times-1.18)$ 
Based on the above regression model, it can be said that by increasing a standard deviation in describing and evaluating others, changes are created in amount of 0.175 in standard deviation of "response rate to pain in cancer patients".

\section{DISCUSSION AND CONCLUSION}

People involved with physical illnesses such as cancer and acute physical disorders always complain of physical problems and injuries and consider themselves in a mass of injuries in this field (11), despite some physical problems and real pains based on illness, many of the damages are rooted in the thinking, assessment, and pessimistic of these individuals which theses negative impulses are the main factor in the development and intensification of negative symptoms associated with the disease (22). Therefore, the type of negative thoughts and negative cognitive thoughts and pessimism to the conditions and future are a major factor in the severity of negative symptoms associated with the disorder (17). For this reason, this study examined two major contrast-oriented concepts with negative cognitive processes with these thoughts in these individuals through mindfulness and positive thinking. The results showed that mindfulness and positive psychology is associated with reducing response to pain of this disorder.

In other words, the results of this research indicated that there is a positive and significant relationship between mindfulness and response to pain in cancer patients. In this regard, Garland et al. (14), in a study consistent with the results obtained in this study, stated that mindfulness encourages positive thinking and thus reduces the response rate to pain in patients. Also, in a study that Shafiee and Amini (2017) on the effectiveness of the Mindfulness-Based Stress Reduction Program, conducted in disaster reduction and pain intensity in patients with chronic musculoskeletal pain reported consistent results with results obtained from this study and stated that mindfulness has a positive effect on pain relief and pain response in patients which can be referred to treat suicidal disorders, pain response, chronic depression, sleep disturbance, general anxiety, anxiety disorder, psychiatric disorders.

It was also observed that there is a positive correlation between positive psychology and the response rate to pain in cancer patients that indicated that patients with positive psychology are better in response rate to pain from the disease. In this regard, Coyne and Tennen (12) also pointed out in their findings that positive psychology in cancer patients has many uses, including the response rate to their pain in disease. Accordingly, their findings can be consistent with the results of this study. This alignment and similarity in the results, on the one hand, are rooted in the coherent structure and similar structural form of this study with other studies, on the other hand, it is an emphasis on the mental process and the thinking process of those involved with severe disorders, which, in the case of intellectual flexibility, positive thinking and the correct, true, and optimistic interpretation of the events can greatly reduce the amount of pressure and physical damages related to disorders and the amount of pain.

\section{DISCUSSION AND CONCLUSION}

People involved with physical illnesses such as cancer and acute physical disorders always complain of physical problems and injuries and consider themselves in a mass of injuries in this field (11), despite some physical problems and real pains based on illness, many of the damages are rooted in the thinking, assessment, and pessimistic of these individuals which theses negative impulses are the main factor in the development and intensification of negative symptoms associated with the disease (22). Therefore, the type of negative thoughts and negative cognitive thoughts and pessimism to the conditions and future are a major factor in the severity of negative symptoms associated with the disorder (17). For this reason, this study examined two major contrast-oriented concepts with negative cognitive processes with these thoughts in these individuals through mindfulness and positive thinking. The results showed that mindfulness and positive psychology is associated with reducing response to pain of this disorder.

\section{REFERENCES}

1. Ahmadvand MA, Manouchehri M. Physiological Psychology. Tehran: Islamic Azad University, Tehran South Branch. 2014.

2. Akbari MI, Nafisi N, Jamshidi Far Z. Effectiveness of Mindfulness Education on Reducing Perceived Stress in Patients with Breast Cancer, Thesis Magazine and Behavior. 2013;7(27):1-11. 
3. Seligman M. Inner happiness. Translated by Tabrizi et al., Tehran: Dangeh Publications Shafiei, Faezeh, Amini Faskhoodi, Maryam. (2017). The Effectiveness of Mindfulness-Based Stress Reduction Program on Disaster Reduction and Pain severity in Patients with Chronic Musculoskeletal Pain. Journal of Anesthesiology and Pain. 2012;7(3):1-10.

4. Taheri NK, Karimi Monghi $H$, Dashtgerd A. Effect of training patient communication skill to nurses on pain reduction of patients, Journal of Anesthesiology and Pain. 2014;5(2):24-32.

5. Teimouri Fard E, Foolad Cheng M. The role of meta-cognition, intelligence and self-efficacy in the academic achievement of high school students. Journal of Learning and Education Studies. 2012;8:136-117.

6. Ghamkhar Fard Z, Toulaiy A. The role of pain beliefs in the severity of pain in headache patients, contemporary psychology. 2010;566-554.

7. Koshtkar E. Strategies for Coping with Perceived Stress and Pain, Karaj: Nekuyan Publications, First Edition. 2017.

8. Gacheel R, Tark DC. Psychology of pain, translation by Dr. Mohammad Ali Asghari Moghadam et al., Tehran:Roshd, First Edition. 2013.

9. Baer RA, Smith GT, Lykins E, Button D, Krietemeyer J, Sauer $S, \ldots$ Williams JMG. Construct validity of the five facet mindfulness questionnaire in meditating and nonmeditating samples. Assessment. 2007;15(3):329-342. https://doi.org/10.1177/1073191107313003 PMid:18310597

10. Bartley T. Mindfulness and Cancer. Mindfulness-Based Cognitive Therapy for Cancer: Gently Turning Towards. 2013;11-22.

11. Colin E, et al. Fortifying the Treatment of Prostate Cancer with Physical Activity. Prostate Cancer. 2016;14. https://doi.org/10.1155/2016/9462975

12. Coyne JC, Tennen H. Positive psychology in cancer care: Bad science, exaggerated claims, and unproven medicine. Annals of behavioral medicine. 2010;39(1):16-26. https://doi.org/10.1007/s12160-009-9154-z PMid:20146038 PMCid:PMC2858800

13. Eiser C. Children with cancer: The quality of life. Routledge. 2006.

14. Garland EL, Farb NA, R. Goldin P, Fredrickson BL. Mindfulness broadens awareness and builds eudaimonic meaning: A process model of mindful positive emotion regulation. Psychological Inquiry. 2015;26(4):293-314. https://doi.org/10.1080/1047840X.2015.1064294 PMid:27087765 PMCid:PMC4826727

15. Grossman P, Van Dam NT. Mindfulness, by any other name...: trials and tribulations of sati in western psychology and science. Contemporary Buddhism. 2011;12(01):219-239. https://doi.org/10.1080/14639947.2011.564841

16. Hinz A, Mehnert A, Kocalevent R-D, Brähler E, Forkmann T, Singer S, Schulte T. Assessment of depression severity with the PHQ-9 in cancer patients and in the general population. BMC Psychiatry. 2016;16:22. http://doi.org/10.1186/s12888-016-0728-6

17. Huang SL, et al. The Potential for Mindfulness-Based Intervention in Workplace Mental Health Promotion: Results of: a Randomized Controlled Trial. Plos Journal. 2015;8. https://doi.org/10.1371/journal.pone.0138089

18. LaVoy ECP, Fagundes $C P$, Dantzer R. Exercise, inflammation, and fatigue in cancer survivors. Exercise Immunology Review. 2016;22:82-93. PMid:26853557 PMCid:PMC4755327

19. Naughton MJ, Weaver KE. Physical and Mental Health among Cancer Survivors: Considerations for Long-Term Care and Quality of Life. North Carolina Medical Journal. 2014;75(4):283-6. https://doi.org/10.18043/ncm.75.4.283

20. Peterson C. Pursuing the good life: 100 reflections in positive psychology. Oxford University Press. 2013.

21. Seligman MEP, Rashid T, Parks AC. Positive psychotherapy. American Psychologist. 2006;61:774-88. https://doi.org/10.1037/0003-066X.61.8.774 PMid:17115810

22. Shonin E, Van Gordon W. The Mechanisms of Mindfulness in the Treatment of Mental Illness and Addiction. International Journal of Mental Health and Addiction. 2016;14(5):844-9. http://doi.org/10.1007/s11469-0169653-7

23. Tanay G, Lotan G, Bernstein A. Salutary proximal processes and distal mood and anxiety vulnerability outcomes of mindfulness training: A pilot preventive intervention. Behavior therapy. 2012;43(3):492-505. https://doi.org/10.1016/j.beth.2011.06.003 PMid:22697439

$\diamond \diamond \diamond \diamond \diamond \diamond \diamond$

http://www.ejgm.co.uk 